\title{
巢湖微囊藻毒素异构体组成的时空分布特征及影响因子
}

\author{
余 丽 $^{1}$, 朱广伟 ${ }^{1 * *}$, 孔繁翔 ${ }^{1}$, 李胜男 ${ }^{2}$, 史小丽 ${ }^{1}$, 张 民 ${ }^{1}$, 阳 振 $^{1}$, 许 海 $^{1}$, 朱梦圆 ${ }^{1}$ \\ ( 1 : 中国科学院南京地理与湖泊研究所, 湖泊与环境国家重点实验室,南京 210008) \\ ( 2 : 湖南省农业科学院, 湖南省农业环境生态研究所,长沙 410125)
}

\begin{abstract}
摘 要: 有害蓝藻释放微囊藻毒素 $(\mathrm{MCs})$, 严重威胁饮用水源地用水安全. 为了解巢湖 MCs 污染状况及其异构体组成对 水质的影响,于 2012 年夏季 ( 8 月) 和秋季 (11 月), 2013 年冬季 ( 2 月) 和春季 (5 月)进行采样分析,研究了巢湖水体中胞 内微囊藻毒素 (IMCs) 和胞外微囊藻毒素 ( EMCs) 异构体的时空分布及其与环境因子的关系. 结果发现, IMCs 和 EMCs 的 平均浓度变化范围分别为 $0.12 \sim 6.45 \mu \mathrm{g} / \mathrm{L}$ 和 $0.69 \sim 1.92 \mu \mathrm{g} / \mathrm{L}$. 在 3 种常见的异构体中, MC-RR 和 MC-LR 比例较高, MC-YR 最低, MC-RR 和 MC-LR 是巢湖水体中 MCs 的主要异构体类型. IMCs 和 EMCs 的异构体浓度及其比例呈现不同的 时空分布特征. 微囊藻生物量、水温、总磷浓度是影响 IMCs 和 EMCs 异构体浓度及其组成变化的关键环境因子. 本研究表 明巢湖富营养化严重的西湖区夏季能合成更多的 MC-RR 异构体, 而秋、冬季节偏向于释放生理毒性更强的 MC-LR 异构 体.了解 MCs 异构体组成变化及其关键影响因素, 有助于预测预警水体 MCs 污染状况和评估饮用水源地 MCs 风险.
\end{abstract}

关键词: 微囊藻毒素;异构体;时空分布;巢湖

\section{Spatiotemporal characteristics of microcystin variants composition and associations with environmental parameters in Lake Chaohu, China}

YU Li ${ }^{1}$, ZHU Guangwei ${ }^{1 * *}$, KONG Fanxiang ${ }^{1}$, LI Shengnan ${ }^{2}$, SHI Xiaoli ${ }^{1}$, ZHANG Min $^{1}$, YANG Zhen ${ }^{1}$, XU Hai $^{1} \&$ ZHU Mengyuan ${ }^{1}$

(1: State Key Laboratory of Lake Science and Environment, Nanjing Institute of Geography and Limnology, Chinese Academy of Sciences, Nanjing 210008, P.R.China)

(2: Hunan Academy of Agricultural Sciences, Hunan Institute of Agricultural Environment and Ecology, Changsha 410125 , P. R. China)

Abstract: The harmful cyanobacteria pose a serious threat to the safety of drinking water sources because of their ability to release microcystins (MCs). To illuminate the status of MCs contamination and the effect of its variants composition on water quality in Lake Chaohu, the temporal and spatial distribution of intracellular microcystins ( IMCs) and extracellular microcystins ( EMCs) and main environmental factors in this lake were examined in summer (August) and autumn ( November) of 2012, winter (February) and spring (May) of 2013, respectively. The results showed that the average concentrations of IMCs and EMCs varied from 0.12 to $6.45 \mu \mathrm{g} / \mathrm{L}$ and from 0.69 to $1.92 \mu \mathrm{g} / \mathrm{L}$, respectively. Among the three common variants, the proportions of MC-LR and MC-RR to total MCs were higher, and the MC-YR was the lowest. MC-RR and MC-LR were the major MCs variants in Lake Chaohu. The concentration and proportion of IMCs and EMCs variants showed different temporal and spatial distribution characteristics. Statistical analysis showed that Microsystis biomass, water temperature, total phosphorus were the key environmental factors affecting the variation in concentration and composition of different MCs variants. This study highlight the fact that the more MC-RR variant can be synthesized in the western Lake with high eutrophication in summer, while more toxic MC-LR variant was released into water in autumn and winter. Understanding the changes of MCs variants composition and its key factors can help to predict the con-

* 国家自然科学基金项目 (41601203，41671494，31800388)、国家水体污染控制与治理科技重大专项 (2017ZX07203001)、中国科学院前沿科学重点研究项目 (QYZDJ-SSW-DQC008) 和中国科学院南京地理与湖泊研 究所“一三五”战略发展规划项目 (NIGLAS2017GH04) 联合资助. 2018-08-29 收稿; 2018-10-21 收修改稿. 余丽 (1984 ), 女,博士;E-mail:yuli514605@163.com.

** 通信作者;E-mail: gwzhu@ niglas.ac.cn. 
taminative status of MCs and assess the risk of MCs in drinking water sources.

Keywords: Microcystins; variants ; temporal and spatial distribution; Lake Chaohu

近年来, 随着经济的快速发展, 湖泊水体富营养化日趋严重, 蓝藻水华频发 ${ }^{[1]}$. 蓝藻水华不仅造成水质 下降, 而且会向水体中释放各种类型藻毒素,危害水生态系统安全 ${ }^{[2-3]}$. 微囊藻毒素 (Microcystins, MCs) 是蓝 藻水华污染中出现频率最高和造成危害最严重的蓝藻毒素, 淡水蓝藻中的微囊藻 (Microcystis) 、鱼腥藻 (Dolichospermum) 和束丝藻 (Aphanizomenon) 是合成 MCs 的主要种属 ${ }^{[4]}$. MCs 是细胞内合成毒素,待细胞裂 解后即释放人水体中表现毒性 ${ }^{[5-6]}$. 它能够强烈抑制蛋白磷酸酶的活性, 还是强烈的肝脏肿瘤促进剂, 不仅 对水生生物产生毒害作用, 还可能通过饮用水和食物链的生物富集危害人类健康 ${ }^{[7]}$. 最早因 MCs 污染引起 人类死亡的报道, 发生于 1996 年的巴西, 由于医院使用被 MCs 污染的血液透析水, 最终导致 88 人发生肝功 能衰竭症状而死亡 ${ }^{[8]}$. MCs 是一类环状七肽化合物, 其环肽结构中含有 $\mathrm{X}$ 和 $\mathrm{Y}$ 两个可变的氨基酸基团, $\mathrm{X}$ 和 $\mathrm{Y}$ 不同的氨基酸组合可以形成不同的 MCs 异构体 ${ }^{[9]}$. 现已发现 100 多种同分异构体, 最常见的是 MC-LR、 MC-RR 和 MC-YR ( L 、 R 和 Y 分别代表亮氨酸、精氨酸和酪氨酸 ${ }^{[10-12]}$, 其中 MC-LR 的急性和生理毒性明显 大于 MC-RR 和 MC-YR, 有较强的致毒性 ${ }^{[13]}$. 正是由于各异构体生理毒性的不同, 它们组成比例的变化将直 接影响水体中毒素污染水平,进而影响饮用水安全.

野外条件下,气象、水文、营养盐等环境条件都有可能对有害蓝藻及其产毒能力产生较大影响. Harke 等 ${ }^{[14]}$ 发现湖体氮浓度和形态会直接影响铜绿微囊藻的毒素产量; Mowe 等 ${ }^{[15]}$ 发现水温能够提高蓝藻的产毒 能力; $\mathrm{Yu}$ 等 ${ }^{[16]}$ 在巢湖蓝藻水华期间调查发现水温、总磷 ( TP ) 和可溶性无机碳是影响 MCs 浓度变化的关键 因子. Shi 等 ${ }^{[17]}$ 通过对太湖 11 年来 MCs 空间分布的估算及分析, 发现光照、水温等环境条件与 MCs 浓度有 密切关系, 甚至风速也能通过对蓝藻水华的空间堆积而影响 MCs 的空间分布. 虽然影响蓝藻生长及产毒能 力的环境因子众多,但不同条件不同藻的产毒能力不同, 产生的毒素异构体种类及组成也不一定相同 ${ }^{[18]}$. 研究表明水温高于 $25^{\circ} \mathrm{C}$ 有利于 MC-RR 的合成, 低于 $25^{\circ} \mathrm{C}$ 则有利于 MC-LR 的合成 ${ }^{[19]}$. 光强的增加会使藻类 偏向合成毒性较强的 MC-LR 异构体 ${ }^{[20]}$. 氮限制条件下增加氮浓度会更有助于 MC-RR 异构体的产生 ${ }^{[21]}$, 而 磷限制条件下则有利于 MC-LR 的合成 ${ }^{[22]}$. 此外, 蔡金傍等 ${ }^{[23]}$ 对华北水库胞外 MCs 异构体年变化的研究显 示, MC-LR 和 MC-RR 两种异构体的组成比例与氮磷比呈正相关.

巢湖 ( $30^{\circ} 25^{\prime} \sim 31^{\circ} 43^{\prime} \mathrm{N}, 117^{\circ} 16^{\prime} \sim 117^{\circ} 51^{\prime} \mathrm{E}$ ) 位于安徽省中部, 是我国第五大淡水湖, 平均水深 $3 \mathrm{~m}$, 水域 面积约 $770 \mathrm{~km}^{2}$, 是长江中下游重要的淡水资源和生态湿地, 同时兼有渔业养殖、航运和旅游功能. 富营养化 的加剧导致蓝藻水华发生的频率逐年增多, MCs 污染也日趋严重. Yu 等 ${ }^{[16]}$ 研究表明, 2012 年巢湖的总 MCs 浓度最大值达到 $17.61 \mu \mathrm{g} / \mathrm{L}$, 而且藻毒素分布广泛, 时空差异明显. 不同营养湖区的水产品如鱼、虾、贝类的 各个组织都有不同程度的藻毒素分布和积累 ${ }^{[24]}$, 甚至当地渔民也被发现体内的血清浓度超标和肝细胞损 伤 ${ }^{[25]}$. 可见, 开展巢湖 MCs 实时监测及对水环境健康危害的研究已刻不容缓. 由于 MCs 各异构体生理毒性 存在差异, 它们在不同环境条件下的相互转化直接反映了水体受 MCs 污染的程度和毒性水平. 因此, 了解关 键环境因子对巢湖 MCs 异构体时空动态变化的影响对于水环境管理和降低水体 MCs 危害有重要意义.

因此, 本研究以巢湖为研究对象, 对水体中 MCs 的异构体进行春、夏、秋、冬四季的调查分析, 研究胞内 微囊藻毒素 (intracellular microcystins, IMCs) 和胞外微囊藻毒素 (extracellular microcystins, EMCs) 异构体浓度 和组成比例的时空分布特征及其关键影响因子, 以探究 MCs 不同异构体的变化对湖泊水环境安全的影响, 为饮用水源地 MCs 的生态风险评估提供理论依据.

\section{1 材料和方法}

\section{1 采样点布设和采样方法}

本研究从东向西依次设置了 9 个采样点 (图 1), 其中采样点 1 3 位于东湖区(东), 采样点 4 6 位于湖 心区 (中), 采样点 7 9 位于西湖区 (西). 期间共进行了 4 次采样, 时间为 2012 年夏季 ( 8 月) 和秋季 (11 月), 2013 年冬季 ( 2 月) 和春季 ( 5 月). 采样过程中用 GPS 系统准确定位, 采用 $2.5 \mathrm{~m}$ 长的 PVC 管采集水柱 的混合水样 $5 \mathrm{~L}$, 混合均匀, 每个采样点采集 3 个平行样. 现场每采样点各取 $500 \mathrm{ml}$ 水样, 用 $1 \%$ 比例的鲁哥 
试剂固定液现场固定, 用于浮游植物的鉴定. 其余所有样品保存在无菌瓶冷藏带回实验室. 采用多功能水质 参数仪 (Yellow Spring Instruments, YSI 6600, USA) 原位测定水温 (Water temperature)、溶解氧 ( DO)、 $\mathrm{pH}$ 和 电导率( Conductivity) 等指标, 水体透明度 $(\mathrm{SD})$ 用塞氏盘现场测定.

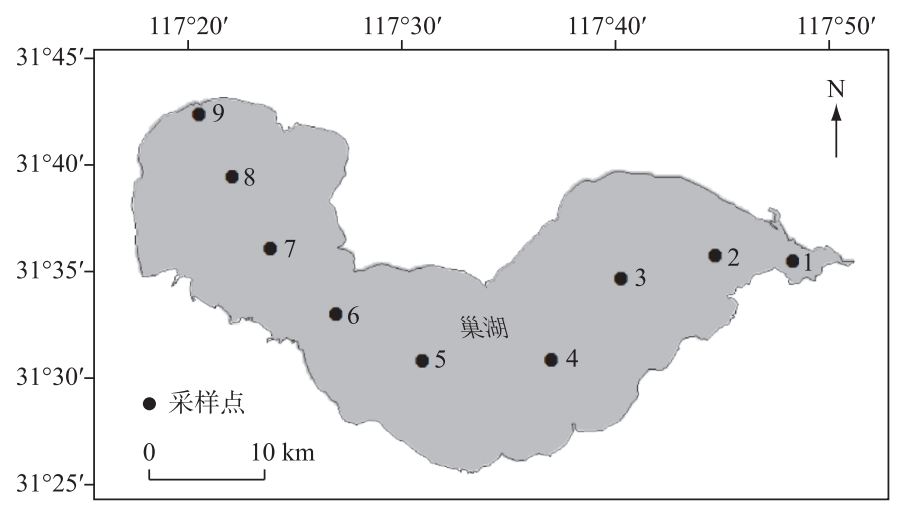

图 1 巢湖采样点分布

Fig.1 Distribution of sampling sites in Lake Chaohu

\section{2 水质指标的测定}

样品带回实验室立即进行各指标测定的预处理. 每采样点取 $100 \mathrm{ml}$ 水样用于水体营养盐的分析, 水体 总氮 ( TN, 原水) 和溶解性总氮 ( DTN, GF/F 膜滤后水) 浓度采用碱性过硫酸钾消解一紫外分光光度法测定; 总磷 ( TP, 原水) 和溶解性总磷 (DTP, GF/F 膜滤后水) 浓度采用碱性过硫酸钾消解一钼锑抗显色分光光度法 测定; 水样通过 $\mathrm{GF} / \mathrm{F}$ 膜滤后用 Skalar 流动注射分析仪测定硝态氮 $\left(\mathrm{NO}_{3}^{-}-\mathrm{N}\right)$ 、亚硝态氮 $\left(\mathrm{NO}_{2}^{-}-\mathrm{N}\right)$ 、铵态氮 $\left(\mathrm{NH}_{4}^{+}-\mathrm{N}\right)$ 和活性磷 $\left(\mathrm{PO}_{4}^{3-}-\mathrm{P}\right)$ 浓度; 溶解性有机碳 ( DOC) 浓度采用 $500^{\circ} \mathrm{C}$ 灼烧 $4 \mathrm{~h}$ 的 $\mathrm{GF} / \mathrm{F}$ 膜过滤 $100 \mathrm{ml}$ 水 样, 然后通过高温灼烧进行测定. 另外, 每采样点取 $100 \mathrm{ml}$ 水样过滤, 采用热乙醇提取一分光光度法分析叶 绿素 a(Chl.a) 浓度 ${ }^{[26]}$.

\section{3 浮游植物鉴定}

现场固定的浮游植物样品在室内静置 $48 \mathrm{~h}$ 后, 吸取上清液, 浓缩到 $30 \mathrm{ml}$, 用于藻类的鉴定, 鉴定参照胡鸿 钧等 ${ }^{[27]}$ 的方法. 每个物种的细胞浓度乘以估计的该物种的细胞体积即为每个物种的生物体积 (Biovolume, $\left.\mathrm{mm}^{3} / \mathrm{L}\right)^{[28]}$, 通常假设浮游植物的密度近似为 $1 \mathrm{mg} / \mathrm{mm}^{3}$, 生物体积可直接转化为生物量 $(\mathrm{mg} / \mathrm{L})$.

\section{4 微囊藻毒素浓度的测定}

根据不同季节微囊藻生物量大小, 用 GF/C 滤膜过滤一定体积水样 (500 1000 ml) 用于 MCs 的测定.滤 膜 $-80^{\circ} \mathrm{C}$ 保存用于测定 IMCs. 滤液置于棕色玻璃瓶中, 用于测定 EMCs.

EMCs 的测定: 取 C18 固相萃取柱, 先用 $10 \mathrm{ml}$ 甲醇和 $10 \mathrm{ml}$ 超纯水活化小柱, 后与 SPE 固相萃取装置连 接. 将滤液通过固相萃取柱 (流速为 $8 \sim 10 \mathrm{ml} / \mathrm{min}$ ) 进行富集, 富集完毕, 先后用 $10 \mathrm{ml}$ 超纯水和 $20 \%$ 的甲醇 溶液淋洗固相萃取柱, 再用 $10 \mathrm{ml}$ 甲醇 (含 $0.1 \%$ 的三氟乙酸) 作为洗脱液洗脱 MCs, 洗脱液收集在玻璃容器 中. $40^{\circ} \mathrm{C}$ 下氮吹浓缩至干, 用 $1 \mathrm{ml}$ 甲醇溶解干物质, 浴旋混合器充分混合 $1 \mathrm{~min}$, 再用小股氮气流吹干, 加 $50 \%$ 的甲醇溶液 $(\mathrm{V} / \mathrm{V}$ ) 定容至 $150 \mu \mathrm{l}$, 待测.

IMCs 的测定:冻干滤膜剪碎至 $2 \mathrm{ml}$ 离心管中,加人 $0.5 \mathrm{~mm}$ 硅珠, $1 \mathrm{ml} 5 \%$ 的乙酸溶液, FastPrep (C)-24 样 品快速制备仪破碎细胞. 破碎样品加人 $10 \mathrm{ml} 5 \%$ 的乙酸溶液, 混匀, 振荡 $30 \mathrm{~min}$ 后, 高速 9500 转/ $\mathrm{min}$ 离心 $10 \mathrm{~min}$, 分离上清液. 残渣再加人 $20 \mathrm{ml} 80 \%$ 的甲醇溶液按上述方法提取 2 次 $^{[29]}$, 合并上清液, GF/C 滤膜过 滤. 滤液按照 1:5的比例用蒸馏水稀释, 然后按照上述测定 EMCs 的方法通过固相萃取柱富集和氮吹浓缩, 最终得到 $150 \mu \mathrm{l}$ 浓缩液, 待测.

高效液相色谱 (HPLC) 法测定:MCs 检测采用美国安捷伦公司 Agilent HPLC1200 高效液相色谱仪,该色 谱仪配有 DAD 检测器. 色谱柱为 Ageilent Eclipse XDB-C18 ( $5 \mu \mathrm{m}, 4.6 \times 150 \mathrm{~mm}$ ), 检测波长 $238 \mathrm{~nm}$, 柱温 
$25^{\circ} \mathrm{C}$, 进样量 $20 \mu \mathrm{l}$, 流速 $1 \mathrm{ml} / \mathrm{min}$. 流动相 $\mathrm{A}$ 为含 $0.04 \%$ 三氟乙酸的超纯水; 流动相 $\mathrm{B}$ 为乙腈, 浓度梯度起 始值为 70\% 流动相 $\mathrm{A}+30 \%$ 流动相 $\mathrm{B}$, 时间为 $10 \mathrm{~min}$; $60 \%$ 流动相 $\mathrm{A}+40 \%$ 流动相 $\mathrm{B}$, 时间为 $15 \mathrm{~min}$. 总 $\mathrm{MCs}$ 的 浓度是 MC-LR、MC-RR 和 MC-YR 3 种异构体微囊藻毒素浓度的总和. MC-LR、MC-RR 和 MC-YR 标准品购买 于 Sigma 公司, 溶于甲醇中, $-20^{\circ} \mathrm{C}$ 冷冻保存备用.

\section{5 数据分析与统计}

本研究中除 $\mathrm{pH}$ 和水温, 其他环境和生物因子、蓝藻(微囊藻和鱼腥藻) 生物量数据都经过 $\log _{10}(x+1)$ 转 换. 数据统计分析由 SPSS16.0 软件包完成. 采用单因素方差分析环境因子、蓝藻生物量和 MCs 浓度的时空 差异, 并通过相关性分析巢湖 MCs、蓝藻生物量与环境因子的关系. 使用 Origin8.5 软件绘图.

\section{2 结果}

\section{1 巢湖环境因子的变化}

监测期间, 水温变化明显, 夏季最高为 $30.75^{\circ} \mathrm{C}$, 冬季最低为 $3.31^{\circ} \mathrm{C}$. Chl.a 浓度呈现时空分布特征: 季节 上, 最大值 $(88.54 \mu \mathrm{g} / \mathrm{L})$ 出现在夏季, 最小值 $(4.30 \mu \mathrm{g} / \mathrm{L})$ 出现在冬季(图 2); 空间上, 表现为西湖区 $>$ 湖心区 $>$ 东湖区 $(P<0.05)$ (表 1). $\mathrm{pH}$ 值变化范围为 $7.01 \sim 9.40$, 最大值出现在夏季, 最小值出现在冬季 (图 2); 空间 上, 表现为西湖区 $>$ 湖心区 $>$ 东湖区 $(P<0.05)$ (表 1) ; 而 DO 浓度与 $\mathrm{pH}$ 相反, 其变化范围为 $4.47 \sim 13.58 \mathrm{mg} / \mathrm{L}$, 最高值出现在冬季, 最低值出现在夏季(图 2); 空间上, 表现为东湖区 $>$ 湖心区 $>$ 西湖区 $(P<0.05)($ 表 1$)$.

巢湖营养盐浓度呈明显的时空分布特征 (图 2) : 季节上, TN 浓度为 $0.56 \sim 6.96 \mathrm{mg} / \mathrm{L}$, 最大值出现在冬 季, 最小值出现在夏季; $\mathrm{DTN} 、 \mathrm{NH}_{4}^{+}-\mathrm{N} 、 \mathrm{NO}_{3}^{-}-\mathrm{N}$ 和 $\mathrm{NO}_{2}^{-}-\mathrm{N}$ 浓度都呈现相似的冬、春季节高于夏、秋季节的变化 规律. TP 浓度为 $0.03 \sim 0.35 \mathrm{mg} / \mathrm{L}$, 最大值出现在春季, 最小值出现在夏季; DTP 浓度为 $0.01 \sim 0.11 \mathrm{mg} / \mathrm{L}$, 最 大值出现在春季, 最小值出现在秋季; $\mathrm{PO}_{4}^{3-}-\mathrm{P}$ 浓度为 $0.0001 \sim 0.0910 \mathrm{mg} / \mathrm{L}$, 最大值出现在夏季, 最小值出现 在冬季. 空间上, 营养盐浓度自东向西逐渐增加, 即: 西湖区 $>$ 湖心区 $>$ 东湖区 $(P<0.05)$. DOC 和电导率也呈 现出类似于营养盐的空间特征,而 SD 则表现出相反的特征(表 1 ).

表 1 巢湖各理化和生物因子的空间变化

Tab.1 Spatial change of physicochemical and biological variables in Lake Chaohu

\begin{tabular}{lccc}
\hline 变量 & 西湖区 $($ 西 $)$ & 湖心区 $($ 中 $)$ & 东湖区 $($ 东 $)$ \\
\hline $\mathrm{TN} /(\mathrm{mg} / \mathrm{L})$ & $3.36(1.06 \sim 6.96)$ & $1.57(0.70 \sim 2.38)$ & $1.06(0.56 \sim 1.59)$ \\
$\mathrm{DTN} /(\mathrm{mg} / \mathrm{L})$ & $2.41(0.34 \sim 6.38)$ & $1.06(0.33 \sim 2.01)$ & $0.71(0.24 \sim 1.54)$ \\
$\mathrm{NH}_{4}^{+}-\mathrm{N} /(\mathrm{mg} / \mathrm{L})$ & $1.24(0.09 \sim 2.39)$ & $0.30(0.11 \sim 0.80)$ & $0.24(0.06 \sim 0.51)$ \\
$\mathrm{NO}_{3}^{-}-\mathrm{N} /(\mathrm{mg} / \mathrm{L})$ & $0.51(0.09 \sim 0.99)$ & $0.29(0.07 \sim 0.66)$ & $0.20(0.08 \sim 0.41)$ \\
$\mathrm{NO}_{2}^{-}-\mathrm{N} /(\mathrm{mg} / \mathrm{L})$ & $0.070(0.001 \sim 0.200)$ & $0.010(0.001 \sim 0.030)$ & $0.004(0.001 \sim 0.010)$ \\
$\mathrm{TP} /(\mathrm{mg} / \mathrm{L})$ & $0.17(0.08 \sim 0.35)$ & $0.07(0.03 \sim 0.13)$ & $0.05(0.03 \sim 0.09)$ \\
$\mathrm{DTP} /(\mathrm{mg} / \mathrm{L})$ & $0.06(0.02 \sim 0.11)$ & $0.02(0.01 \sim 0.03)$ & $0.01(0.01 \sim 0.03)$ \\
$\mathrm{PO}{ }_{4}^{3-}-\mathrm{P} /(\mathrm{mg} / \mathrm{L})$ & $0.0250(0.0020 \sim 0.0910)$ & $0.0040(0.0001 \sim 0.0130)$ & $0.0030(0.0010 \sim 0.0060)$ \\
$\mathrm{DOC} /(\mathrm{mg} / \mathrm{L})$ & $5.52(4.34 \sim 7.72)$ & $4.50(3.92 \sim 4.90)$ & $4.36(3.61 \sim 5.13)$ \\
$\mathrm{SD} / \mathrm{cm}$ & $52.83(20.0 \sim 110.0)$ & $54.17(20.0 \sim 90.0)$ & $66.25(30 \sim 110)$ \\
水温 $/{ }^{\circ} \mathrm{C}$ & $16.90(3.35 \sim 30.04)$ & $16.82(3.31 \sim 30.41)$ & $17.40(3.62 \sim 30.75)$ \\
电导率/ $(\mu \mathrm{S} / \mathrm{cm})$ & $390.0(290.0 \sim 721.0)$ & $300.2(184.8 \sim 361.0)$ & $298.4(182.0 \sim 359.0)$ \\
$\mathrm{pH}$ & $8.14(7.01 \sim 9.40)$ & $8.01(7.07 \sim 9.36)$ & $7.90(7.09 \sim 9.12)$ \\
$\mathrm{DO} /(\mathrm{mg} / \mathrm{L})$ & $8.31(4.47 \sim 13.00)$ & $8.35(4.97 \sim 13.58)$ & $8.71(5.20 \sim 13.13)$ \\
$\mathrm{Chl} . \mathrm{a} /(\mu \mathrm{g} / \mathrm{L})$ & $33.90(10.55 \sim 88.54)$ & $21.86(7.80 \sim 89.40)$ & $12.17(4.30 \sim 3.48)$ \\
\hline
\end{tabular}

\section{2 蓝藻优势属的生物量变化}

根据 4 个季度 9 个采样点的平均生物量, 鱼腥藻为第 1 优势属, 占蓝藻总生物量的 $88.21 \%$, 微囊藻为第 2 优势属, 占 $11.20 \%$, 束丝藻占 $0.39 \%$, 其他属则占比较低( 图 3). 可见, 鱼腥藻和微囊藻为巢湖蓝藻的主要 优势属, 且两优势属呈不同的时空变化: 季节上, 微囊澡生物量在夏季最高, 为 $20.24 \mathrm{mg} / \mathrm{L}$, 冬季最低, 为 

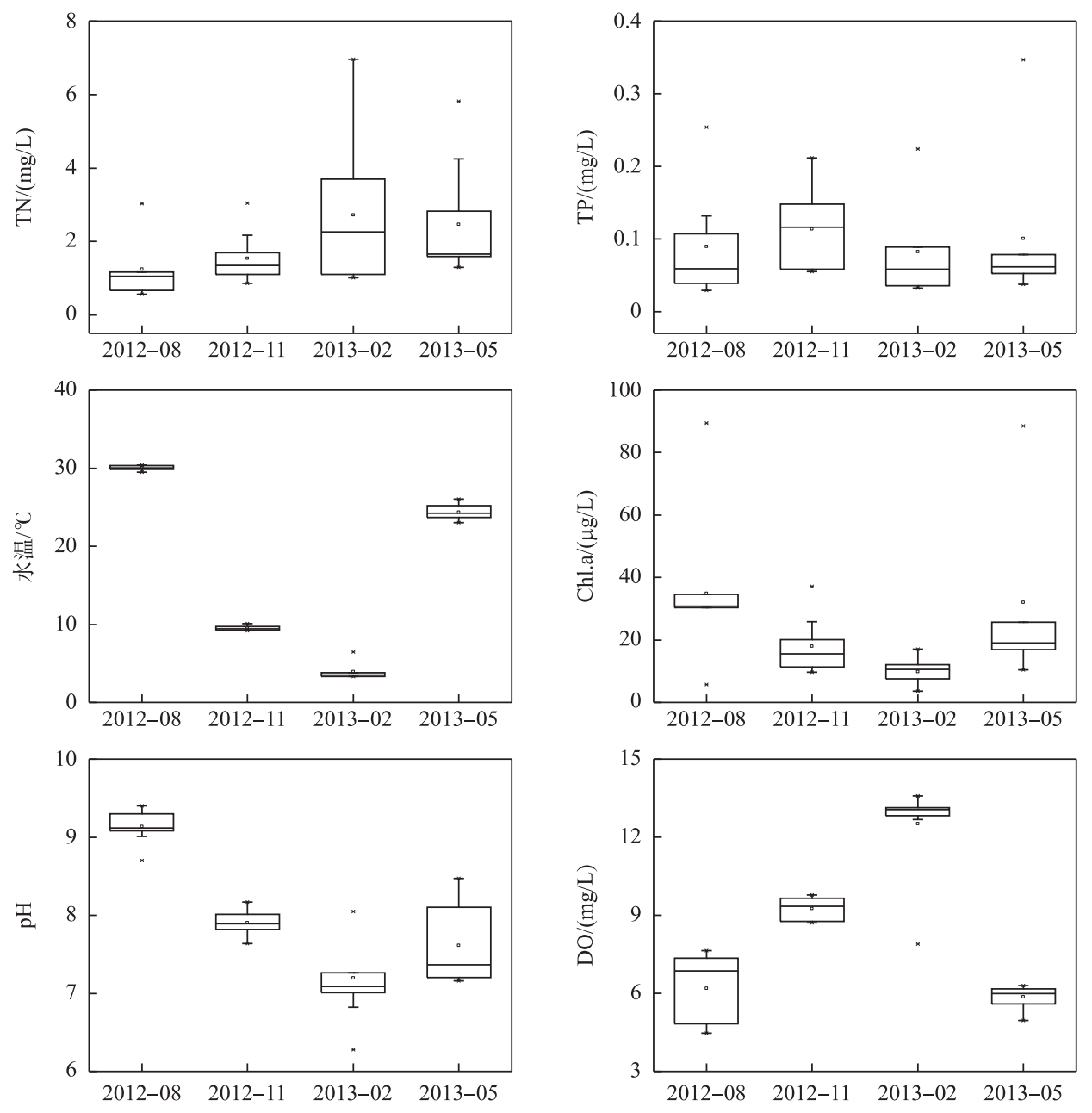

图 2 巢湖理化因子和生物因子的季节变化

Fig.2 Seasonal changes of physicochemical and biological variables in Lake Chaohu

$0.04 \mathrm{mg} / \mathrm{L}$; 鱼腥藻在秋季和春季生物量较高, 平均生物量分别为 73.23 和 $89.22 \mathrm{mg} / \mathrm{L}$, 而冬季最低, 为 5.95 $\mathrm{mg} / \mathrm{L}$. 空间上, 微囊藻最高生物量集中在西湖区; 而鱼腥藻夏季最高生物量出现在湖心区, 秋季集中在东部 湖区,冬、春季又多集中在西部湖区 (图 4).

\section{3 总微囊藻毒素的动态变化}

研究期间,9 个采样点藻毒素浓度检出率为 100\%, 且不同湖区的 MCs 存在明显的动态变化. 总 MCs 浓 度范围为 $0.28 \sim 17.61 \mu \mathrm{g} / \mathrm{L}$, 最高值出现在夏季的西湖区, 最小值出现在冬季的东湖区 (图 5 ).

构成总 MCs 的 IMCs 和 EMCs 表现出相同的季节变化: 夏季 IMCs 平均浓度最高, 为 $6.45 \mu \mathrm{g} / \mathrm{L}$, 秋季和 冬季分别降至 2.06 和 $0.12 \mu \mathrm{g} / \mathrm{L}$, 而春季又升至 $4.45 \mu \mathrm{g} / \mathrm{L}$. 夏、秋、冬和春季 4 个季度 $\mathrm{EMCs}$ 平均浓度分别为 $1.92 、 1.27 、 0.69$ 和 $0.87 \mu \mathrm{g} / \mathrm{L}$. 同时, IMCs 和 EMCs 浓度存在明显的交替变化,夏、秋和春季的 IMCs 平均浓度 均明显高于 $\operatorname{EMCs}(P<0.05)$, 而冬季 IMCs 平均浓度低于 $\operatorname{EMCs}(P<0.05)$ ( 图 5$)$.

空间上, IMCs 和 EMCs 均呈现出西湖区 > 湖心区 $>$ 东湖区 $(P<0.05)$ 的分布特征, 东湖区 IMCs 和 EMCs 浓 度变化范围分别为 $0.10 \sim 2.75$ 和 $0.17 \sim 1.13 \mu \mathrm{g} / \mathrm{L}$; 湖心区分别为 $0.91 \sim 13.24$ 和 $0.31 \sim 3.15 \mu \mathrm{g} / \mathrm{L}$; 西湖区分 别为 $0.14 \sim 15.91$ 和 $1.02 \sim 3.19 \mu \mathrm{g} / \mathrm{L}$. IMCs 和 EMCs 的最大值 15.91 和 $3.19 \mu \mathrm{g} / \mathrm{L}$ 分别出现在春季和夏季的 西湖区,最低值 0.10 和 $0.17 \mu \mathrm{g} / \mathrm{L}$ 均出现在冬季的东湖区(图 5 ). 


\section{4 微囊藻毒素异构体的时空变化}

研究结果显示巢湖 MCs 主要含有 MC-LR、MC$\mathrm{RR}$ 和 MC-YR 3 种异构体. 3 种异构体的平均浓度 分别为 $1.81 、 2.07$ 和 $0.47 \mu \mathrm{g} / \mathrm{L}$. 其中, MC-RR 所占 比例最大 $(47.46 \%)$, 其次为 MC-LR $(41.66 \%)$, MCYR 占比最小 ( $10.88 \%)$. MC-LR 和 MC-RR 是巢湖 水体中最主要的异构体 (图 6).

3 种异构体组成比例呈现明显的时空差异. 季 节上, MC-LR 所占比例为冬季 $(77.02 \%)>$ 秋季 $(49.36 \%)$ ) 春季 $41.66 \%>$ 夏季 $(37.91 \%)(P<0.05)$, MC-RR 则相反, 为夏季 $(52.11 \%)>$ 春季 $(48.27 \%)>$ 秋季 $(43.14 \%)>$ 冬季 $(13.03 \%)(P<0.05)$, MC-YR 为春季 $(14.74 \%)>$ 夏季 $(9.97 \%)>$ 冬季 $(9.94 \%)>$ 秋 季 $(7.50 \%)(P<0.05)$ (图 6a). 空间上, MC-LR 的分 布规律为东湖区 $(51.05 \%)>>$ 湖心 区 $(41.58 \%)>$ 西湖 区 $(39.83 \%)(P<0.05)$, MC-RR 为西湖区 $(49.54 \%)>$ 湖心区 $(46.01 \%)>$ 东湖区 $(40.40 \%)(P<0.05)$, 而 MC-YR 呈现出湖心区 $(12.40 \%)>$ 西湖区 $(10.62 \%)>$ 东湖区 $(8.55 \%)(P<0.05)$ 的分布特征 (图 $6 \mathrm{~b})$.

IMCs 的 3 种异构体的浓度呈现时空变化. 季节 上, 3 种异构体均呈夏季最高,秋季降低,冬季最低, 随后春季又升高的变化趋势. 空间上,均为西湖区>

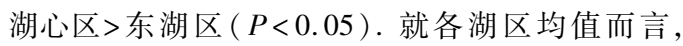
IMC-LR 的最大值 $(3.59 \mu \mathrm{g} / \mathrm{L})$ 出现在春季的西湖 区, 最小值 $(0.03 \mu \mathrm{g} / \mathrm{L})$ 出现在冬季的东湖区. IMC$R R$ 最大值 $(8.12 \mu \mathrm{g} / \mathrm{L})$ 出现在夏季的西湖区, 最小 值 $(0.25 \mu \mathrm{g} / \mathrm{L})$ 出现春季的东湖区. IMC-YR 的最大 值 $(1.31 \mu \mathrm{g} / \mathrm{L})$ 出现在春季的西湖区, 最小值 $(0.02$ $\mu \mathrm{g} / \mathrm{L}$ ) 出现在夏季的东湖区 (图 7a). 3 种异构体所 占比例变化也呈不同的时空特征: IMC-LR 在 8、11、 2 和 5 月的平均比例分别为 $40.27 \% 、 36.06 \%$ 、 $29.62 \%$ 和 $33.19 \%$, 呈现从夏季到秋、冬季降低, 而春 季升高的趋势. IMC-RR 在 $8 、 11 、 2$ 和 5 月的平均比 例分别为 $50.55 \% 、 56.89 \% 、 45.93 \%$ 和 $48.83 \%$, 呈现 从夏季到秋季升高、秋季到冬季降低,春季又增高的 趋势. IMC-YR 在 $8 、 11 、 2$ 和 5 月的平均比例分别为 $9.18 \% 、 7.04 \% 、 24.45 \%$ 和 $19.31 \%$, 呈现出夏、秋季 低,而冬、春季高的趋势. 空间上, IMC-LR 所占比例 为东湖区 $>$ 湖心区 $>$ 西湖区 $(P<0.05)$, IMC-RR 所占 比例为西湖区 $>$ 湖心 区 $>$ 东湖 区 $(P<0.05)$, 而 IMC-YR 所占比例在 5 和 8 月为湖心区 $>$ 西湖区 $>$ 东 湖区 $(P<0.05), 11$ 和 2 月为东湖区 $>$ 湖心区 $>$ 西湖区 $(P<0.05)$ (图 7b). 结果显示胞内异构体 IMC-RR 平 均比例最高, 为胞内优势毒素种类.

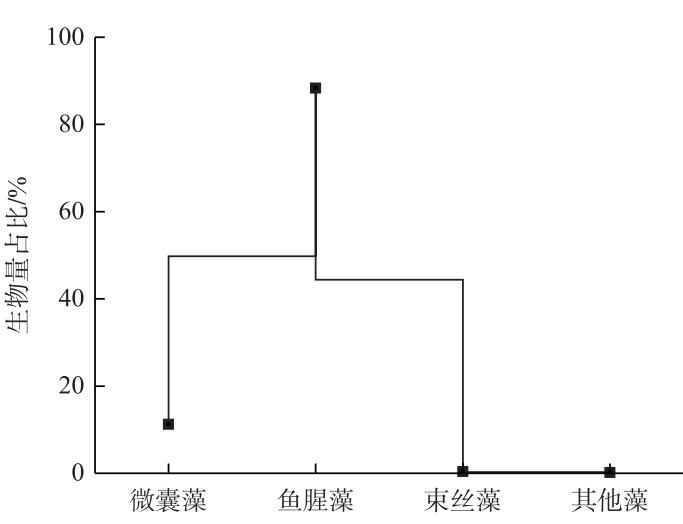

图 3 巢湖蓝藻主要属的平均生物量占比

Fig.3 Percentage of average biomass of the main genera of cyanobacteria community in Lake Chaohu

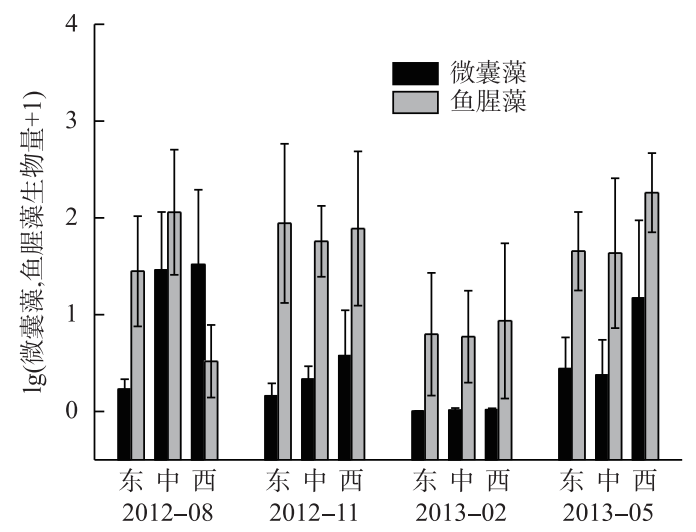

图 4 微囊藻和鱼腥藻的时空变化

Fig.4 Temporal and spatial variation of

Microcystis and Dolichospermum

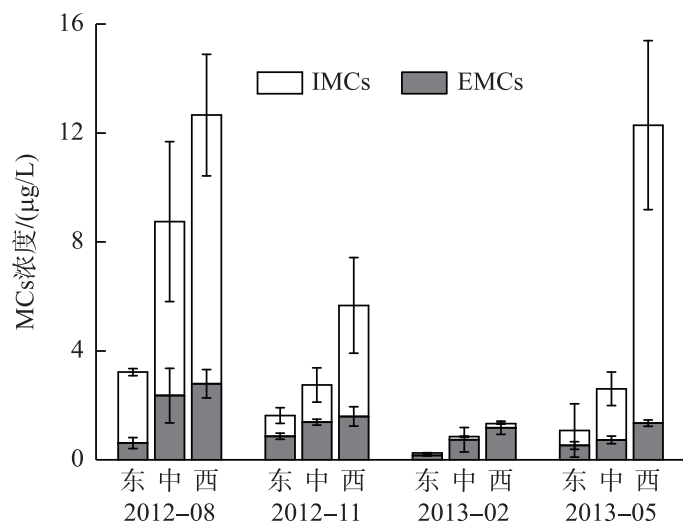

图 5 巢湖不同湖区胞内和胞外微囊藻毒素浓度变化

Fig.5 Variation of IMCs and EMCs concentrations in different parts of Lake Chaohu 


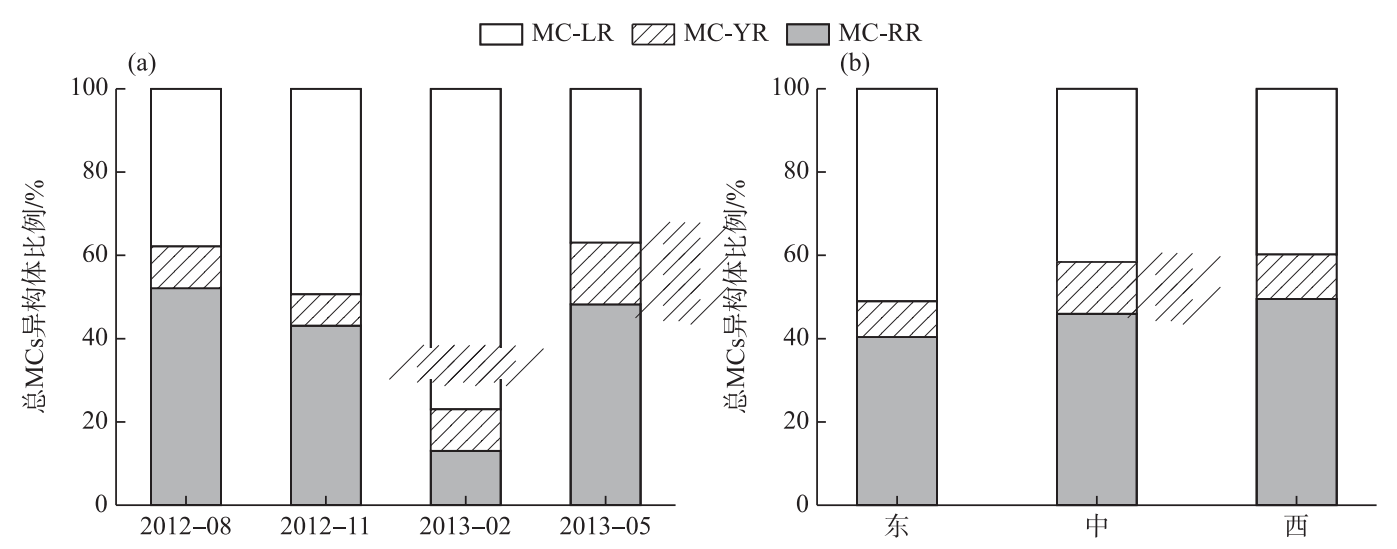

图 6 巢湖总微囊藻毒素异构体组成的时间 (a) 和空间 (b) 变化

Fig.6 Temporal (a) and spatial (b) variation of total MCs variants composition in Lake Chaohu

(a)

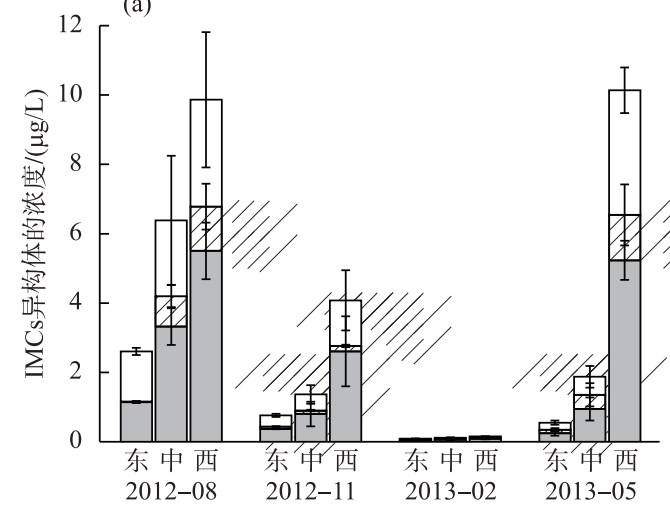

IMC-YR $\square$ IMC-RR

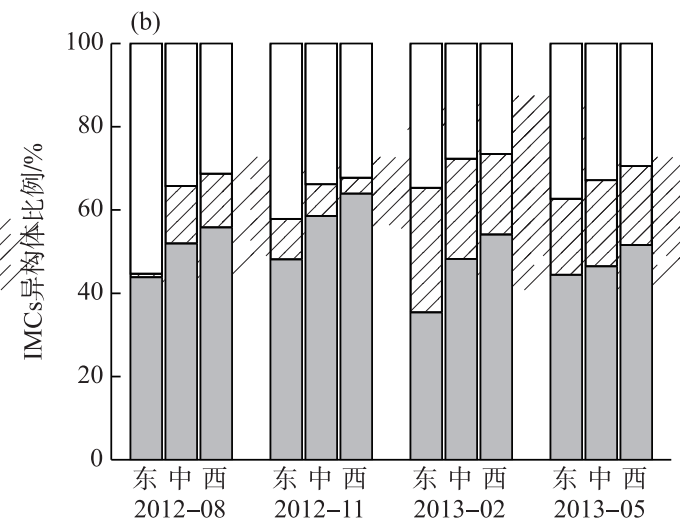

图 7 胞内微囊藻毒素异构体浓度 (a) 及其组成比例 (b) 的时空分布

Fig.7 Temporal and spatial variations in the concentrations of IMCs variants (a) and their composition (b)

EMCs 的 3 种异构体的时空变化不同于 IMCs. 季节上, 3 种异构体平均浓度的变化趋势不完全一致, EMC-LR 平均浓度在夏季至秋季增加, 秋季达到最高, 而冬、春季降低, 春季达到最低. EMC-RR 平均浓度在 夏季最高, 秋、冬季降低,冬季降至最低, 而春季又升高. EMC-YR 平均浓度呈现从夏季至秋季增加, 秋季最 高, 而冬季降至最低,春季又升高的趋势. 空间上, 3 种异构体均为西湖区 > 湖心区 $>$ 东湖区 $(P<0.05)$. 就各湖 区均值而言, EMC-LR 和 EMC-RR 的最大值 ( 1.33 和 $1.32 \mu \mathrm{g} / \mathrm{L})$ 均出现在夏季的西湖区, 最小值 $(0.08$ 和 $0.04 \mu \mathrm{g} / \mathrm{L})$ 均出现在冬季的东湖区, 而 EMC-YR 的最大值 $(0.17 \mu \mathrm{g} / \mathrm{L})$ 出现在春季的西湖区, 最小值 $(0.04$ $\mu \mathrm{g} / \mathrm{L}$ ) 出现在夏季的东湖区 (图 8a). 3 种异构体的所占比例也表现出不同的时空分布特征: EMC-LR 在 8 、 $11 、 2$ 和 5 月的平均比例分别为 $44.44 \% 、 73.83 \% 、 75.94 \%$ 和 $46.65 \%$, 呈现从夏季到冬季升高, 春季又降低的 趋势. EMC-RR 在 8、11、2 和 5 月的平均比例分别为 50.34\%、15.05\%、11.48\% 和 $36.06 \%$, 呈现从夏季到秋、冬 季降低, 春季又升高的趋势. EMC-YR 在 $8 、 11 、 2$ 和 5 月的平均比例分别为 $5.22 \% 、 11.10 \% 、 12.58 \%$ 和 $17.28 \%$, 呈现从夏季到来年春季逐渐升高的趋势. EMCs 异构体中 EMC-LR 所占比例较高, 为最主要异构体, 尤其在秋、冬季节. 空间上, EMC-LR 所占比例为西湖区 > 湖心区 $>$ 东湖区 $(P<0.05)$, EMC-RR 所占比例为东 湖区 $>$ 湖心区 $>$ 西湖区 $(P<0.05)$, EMC-YR 所占比例为东湖区 $>$ 湖心区 $>$ 西湖区 $(P<0.05)($ 图 $8 b)$. 


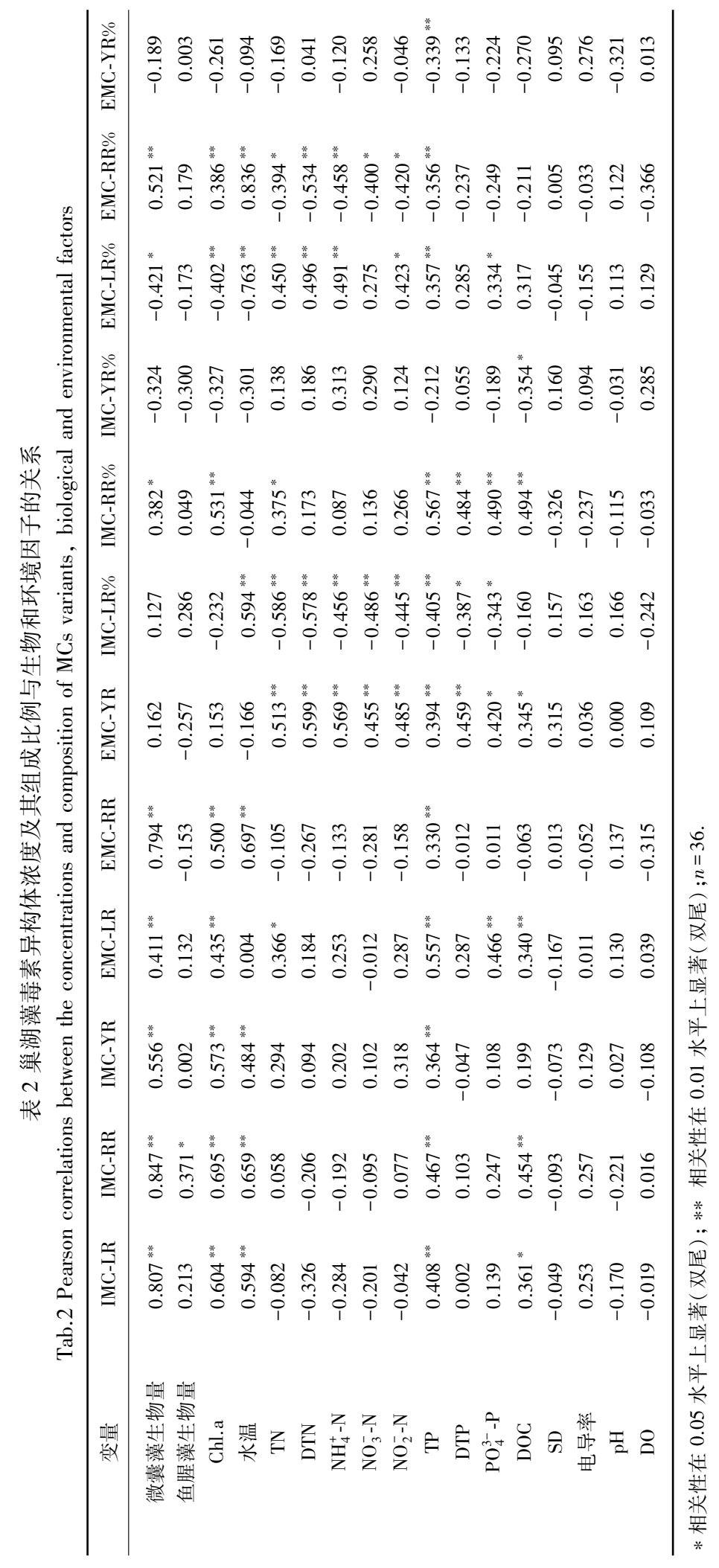




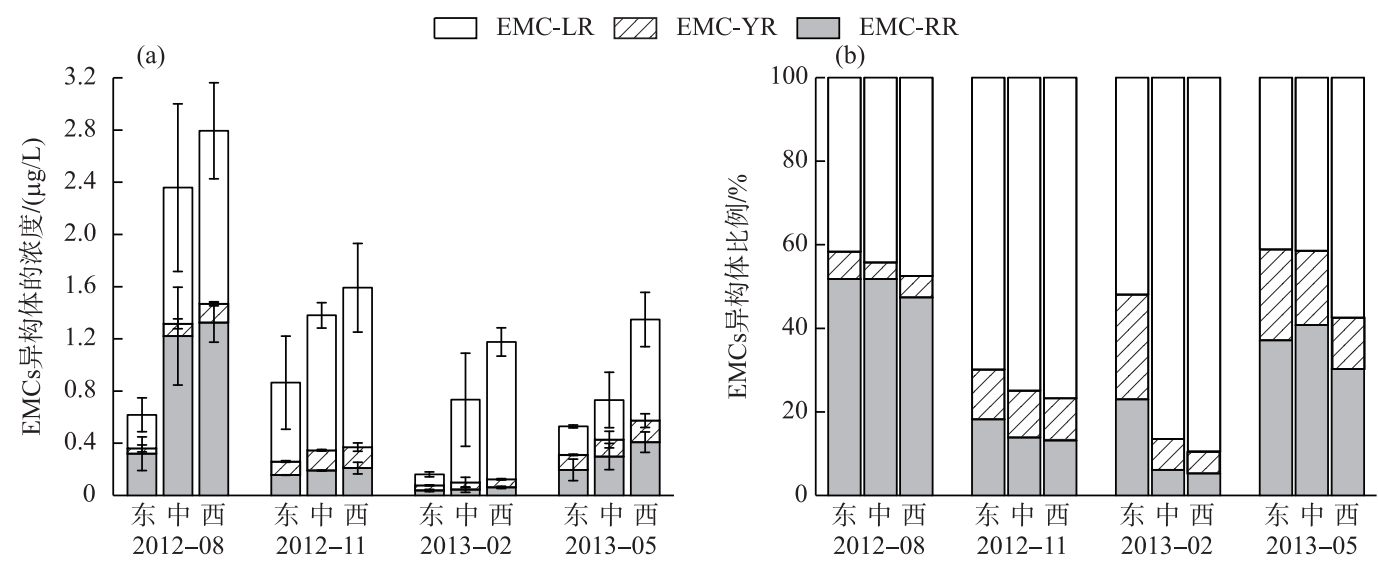

图 8 胞外微囊藻毒素异构体浓度 (a) 及其组成比例 (b) 的时空分布

Fig.8 Temporal and spatial variations in the concentrations of EMCs variants (a) and their composition (b)

\subsection{IMCs 和 EMCs 异构体变化与生物和环境因子的关系}

相关分析结果 (表 2) 表明: IMCs 的 3 种异构体浓度与微囊藻生物量、Chl. a 浓度、水温、TP 浓度均呈极 显著正相关 $(P<0.01)$. IMCs 的 3 种异构体中仅有 IMC-RR 与鱼腥藻生物量呈显著相关 $(P<0.05)$, 但明显低 于其与微囊藻的相关性. 而 EMCs 的 3 种异构体浓度与环境因子的相关关系却不一致: EMC-LR 浓度与微囊 藻生物量、Chl.a 、 TN、TP、 $\mathrm{PO}_{4}^{3-}-\mathrm{P}$ 和 DOC 浓度呈极显著正相关 $(P<0.01)$; EMC-RR 浓度与微囊藻生物量、 Chl. a 浓度、水温、TP 浓度呈显著正相关 $(P<0.01)$; EMC-YR 浓度与 TN、TP、各形态 N、各形态 $\mathrm{P} 、 \mathrm{DOC}$ 浓度呈 显著正相关 $(P<0.05)$. IMCs 和 EMCs 3 种异构体所占比例与环境因子的相关关系也各不同: IMC-LR\%与水 温呈极显著正相关 $(P<0.01)$, 而与 TN、TP、各形态 $\mathrm{N}$ 、各形态 $\mathrm{P}$ 浓度呈显著负相关 $(P<0.01)$; IMC-RR\% 与微 囊藻生物量、Chl.a、TN、TP、 $\mathrm{PO}_{4}^{3-}-\mathrm{P}$ 和 DOC 浓度呈显著正相关 $(P<0.05)$; IMC-YR\% 仅与 DOC 浓度呈显著负 相关 $(P<0.05)$. EMC-LR\% 与微囊藻生物量、Chl. a 浓度和水温呈显著负相关 $(P<0.05)$, 而与 TN、DTN、 $\mathrm{NH}_{4}^{+}-\mathrm{N} 、 \mathrm{NO}_{2}^{-}-\mathrm{N} 、 \mathrm{TP} 、 \mathrm{PO}_{4}^{3-}-\mathrm{P}$ 浓度呈显著正相关 $(P<0.05) ; \mathrm{EMC}-\mathrm{RR} \%$ 与微囊藻生物量、Chl.a 浓度和水温呈极 显著正相关 $(P<0.01)$, 而与 TN 、各形态 $\mathrm{N} 、 \mathrm{TP}$ 浓度呈显著负相关 $(P<0.05) ; \mathrm{EMC}-\mathrm{YR} \%$ 仅与 TP 浓度呈显著 负相关 $(P<0.05)$.

\section{3 讨论}

\section{1 微囊藻是巢湖 MCs 的主要贡献者}

本研究结果显示, 微囊藻和鱼腥藻是巢湖水华蓝藻优势属, 且呈不同的时空演替模式. 夏季微囊藻为优 势属, 秋、冬和春季鱼腥藻为优势属; 微囊藻主要分布在西湖区,而鱼腥藻在不同季节、不同湖区都有分布. 这与 Zhang 等 ${ }^{[30]}$ 对巢湖的研究结果相一致. 微囊藻和鱼腥藻是蓝藻中产生 MCs 的主要属 ${ }^{[4]}$, 虽然研究发现 巢湖鱼腥藻的平均生物量明显高于微囊藻 (图 4), 但其与 MCs 浓度的相关性较低, 且只与 IMC-RR 异构体浓 度相关 $(r=0.371, P<0.05)$, 而微囊藻生物量却与 MCs 浓度呈极显著相关 $(r=0.847, P<0.01)$. 尤其在蓝藻 水华期间, 微囊藻生物量最高, 而此时的 MCs 浓度也是全年最高的 (图 4、5). 可见, 巢湖微囊藻是 MCs 的主 要贡献者 ${ }^{[31]}$, 但不排除生物量占优势的鱼腥藻对 MCs 的影响.

\subsection{IMCs 和 EMCs 异构体浓度变化的影响因子}

蓝藻水华期间 IMCs 浓度明显高于 EMCs 浓度,而冬季则呈现 EMCs 浓度高于 IMCs 浓度的反向变化关 系 (图 5). 这与蔡金傍等 ${ }^{[23]}$ 对水库 MCs 的研究结果相一致, 原因主要与产毒蓝藻生物量和 MCs 的合成与释 放有关. MCs 为细胞内合成毒素, 春、夏季蓝藻水华期间微囊藻处于对数生长期, 生物量逐渐增加, 胞内合成 MCs 增多; 待微囊藻生物量趋于峰值时, MCs 浓度也达到最大值, 而此时微囊藻细胞以合成 IMCs 为主, 释放 人水体的 EMCs 较少, 故而 IMCs 浓度高于 EMCs 浓度; 而进人秋、冬季节, 微囊藻生物量显著降低, 加之藻细 
胞逐渐衰亡裂解, 毒素大量释放到水体中, 当释放量大于水体 MCs 吸附量和降解量时, 即呈现水体中 $\mathrm{EMCs}$ 浓度高于 IMCs 浓度的现象.

本研究显示巢湖 IMCs 和 EMCs 的常见异构体为 MC-LR、MC-RR 和 MC-YR, 但整个研究期间 MC-YR 浓 度较低, 而 MC-RR 和 MC-LR 所占比例较大, 为主要的异构体. 李印霞 ${ }^{[32]}$ 的研究也得到过相同结论, 而杨华 等 $^{[31]}$ 对巢湖的调查却表明 MCs 以 MC-LR 为主, MC-RR 仅在 6-9 月出现. 这可能与不同时间不同采样点调 查导致的差异有关. 整个研究期间, IMCs 和 EMCs 的 3 种异构体呈不同的时空分布特征(图 7、8). 前人研究 表明水温、光和营养盐等会影响 MCs 的合成 ${ }^{[33-35]}$, 但由于地理距离和湖泊环境条件的不同,结论各不一致. 而本研究相关分析则表明微囊藻生物量、Chl.a 浓度、水温和 TP 浓度是影响 MCs 浓度变化的关键因子.

水温是影响蓝藻生长和 $\mathrm{MCs}$ 合成的重要驱动因子 ${ }^{[36-37]}$, 微囊藻最适宜生长水温为 $25^{\circ} \mathrm{C}$ 以上 ${ }^{[38]}$. 水温的 升高不仅促进微囊藻的生长, 而且有助于 $\mathrm{MCs}$ 的增加 ${ }^{[37]}$. 本研究夏季 ( 8 月) 平均水温为 $30^{\circ} \mathrm{C}$, 适宜产毒微 囊藻生长, 微囊藻生物量和 Chl. a 浓度增加, 胞内合成的各异构体浓度也升高. 进人秋季水温降低, 不再适合 微囊藻生长, 其生物量和 Chl. a 浓度随之下降, 各异构体浓度也逐渐下降, 至冬季 ( 2 月) 最低水温为 $3.86^{\circ} \mathrm{C}$, 生物量最低, 3 种异构体浓度也达到最低值, 但至春季 5 月水温回升, 3 种异构体的浓度又升高. 可见,水温 可能是通过影响微囊藻生物量进而影响 MCs 浓度的变化. 微囊藻生物量与 IMCs 的 3 种异构体浓度的极显 著正相关也说明了此关系 (表 2). 同样是蓝藻水华暴发严重的太湖, 调查也显示水温与微囊藻生物量和 $\mathrm{MCs}$ 浓度呈显著正相关 ${ }^{[39]}$. 这些结果预示未来气候变暖将会增加产毒微囊藻水华的强度和 MCs 浓度 ${ }^{[38]}$. 然而与 IMCs 不同, EMCs 异构体中仅 EMC-RR 浓度与水温呈极显著相关, 而 EMC-LR 和 EMC-YR 浓度与水 温没有显著相关性 (表 2). 究其原因, 可能是由于 EMC-RR 浓度与水温季节变化存在一致性, 而 EMC-LR 和 EMC-YR 浓度变化则不同 (图 8). 另外, 自然条件下 EMCs 的释放过程同时伴随着降解或转化过程, 较为复 杂 ${ }^{[40-41]}$, 各种异构体对不同环境因子的响应也有所不同, 因而 IMCs 比 EMCs 的变化更具有规律性.

磷通常是湖泊中的限定因子, 磷浓度的较小变化就能影响蓝藻生长和 MCs 的合成 ${ }^{[42-43]}$, Rinta-Kanto 等 ${ }^{[44]}$ 对 Erie 湖的 MCs 和环境因子监测发现, 磷浓度和 MCs 浓度呈极显著正相关. Kotak 等 $^{[45]}$ 对加拿大的富 营养化湖泊调查显示磷浓度的升高能促进产毒蓝藻水华发生和 MCs 浓度的升高. 而本研究结果也显示 IMCs 和 EMCs 的各异构体浓度均与 TP 浓度呈极显著正相关, 表明 TP 是影响 IMCs 和 EMCs 各异构体变化 的关键驱动因子, 而这个驱动的机制主要表现在对 MCs 空间差异的影响. 由于巢湖西部水域承接了来自南 汁河、十五里河、派河和塘西河等河流大量的生活污水、工业废水以及农业面源污染, 同时该区域环境背景 磷浓度受磷矿影响明显偏高, 所以西湖区较高的磷浓度提供了产毒蓝藻水华发生的重要物质基础, 致使产 毒微囊藻水华呈现西湖区明显高于湖心和东湖区的趋势. 相应地, IMCs 和 EMCs 各异构体浓度的空间分布 也呈现相同的变化特征. 虽然 TP 浓度的影响较为显著, 但 MCs 是一种富含氮的氨基酸组成的七肽化合物, 提高氮浓度会促进产毒微囊藻的生长和 MCs 的合成与释放 ${ }^{[46]}$. 本研究的相关分析也表明 EMC-LR 和 EMC-YR 浓度与 TN 浓度呈显著正相关, 尤其是 EMC-YR 浓度与不同形态氮浓度均呈极显著正相关 (表 2). 另外, 在本研究中 DOC 浓度与 IMCs、EMCs 的不同异构体浓度呈显著正相关, 表明 DOC 也会影响 MCs 的合 成和异构体的种类. Su 等 ${ }^{[47]}$ 对太湖的 MCs 研究也显示 DOC 是影响 MCs 不同异构体浓度变化的因子之一.

\subsection{IMCs 和 EMCs 异构体组成比例变化的影响因子}

巢湖总 MCs 异构体组成呈明显的时空演替模式, 主要异构体 MC-LR 和 MC-RR 所占比例呈反向变化 (图 6), 这与 IMCs 和 EMCs 异构体的组成变化密切相关. IMCs 异构体平均比例为 IMC-RR > IMC-LR > IMC-YR, 而 EMCs 异构体平均比例为 EMC-LR $>$ EMC-RR $>$ EMC-YR, 且 3 种异构体呈现不同的时空差异. 相关 分析表明水温和氮、磷营养盐浓度是影响 3 种异构体所占比例时空分布的关键因子, 但又有所不同 (表 2).

水温是影响不同 MCs 异构体组成的重要因子, 水温低于 $25^{\circ} \mathrm{C}$ 时主要合成 MC-LR, 高于 $25^{\circ} \mathrm{C}$ 时主要产生 $M C-R R^{[19]}$. 本研究中夏季 ( 8 月) 水温高于 $25^{\circ} \mathrm{C}$, 有利于合成 MC-RR, 此时 IMC-RR 平均比例明显高于 IMC-LR 和 IMC-YR (图 7). 进人秋、冬季水温低于 $25^{\circ} \mathrm{C}$, 有利于合成 IMC-LR, 但此时 IMC-LR 并未占优势, 仍 是 IMC-RR 占有较高比例. 这可能与秋、冬季节藻细胞衰亡裂解并向水体释放 MCs, 而 IMC-RR 由胞内向胞 外释放有较长的滞后期有关 ${ }^{[48]}$. 至春季 5 月, 水温上升至 $25^{\circ} \mathrm{C}$, 胞内又偏向合成 IMC-RR, 因而 IMC-RR 在整 个研究期间一直维持较高比例. IMC-LR 比例变化与水温呈极显著正相关 $(r=0.594, P<0.01)$, 表明其与水 
温变化相一致, 本研究结果也显示夏季的 IMC-LR 比例明显高于其他季节. 而 IMC-YR 比例则与水温没有任 何相关性 $(r=-0.301, P>0.05)$. EMCs 异构体中 EMC-RR 和 EMC-LR 所占比例在季节上呈反向变化, 因此水 温与 EMC-RR 呈极显著正相关 $(r=0.836, P<0.01)$, 与 EMC-LR $(r=-0.763, P<0.01)$ 呈极显著负相关, 而 EMC-YR 所占比例与水温却没有显著相关性 $(r=-0.094, P>0.05)$ (表 2). EMCs 异构体中 EMC-LR 平均比 例较高, 尤其以冬季 (2 月) 最高. 可能与 MCs 由胞内释放到胞外, MC-LR 异构体释放的速度要明显高于 MC-RR 有关 ${ }^{[49]}$. 然而, 本研究中夏季 ( 8 月) EMC-RR 却占有较高的比例, 可能是因为正值水华蓝藻生长期, 以胞内合成 MCs 为主, 释放到水体中的毒素较少 ${ }^{[50]}$, 此时水中 EMCs 浓度的贡献较少来源于细胞的衰亡和 裂解, 而主要是生长期偏向合成 MC-RR 有毒藻株的代谢 ${ }^{[51]}$. 另一方面, 此期间富营养化水体和高温强光照 条件有利于可降解 MCs 的微生物等的繁殖, 而其对 MC-RR 的降解速率较低 ${ }^{[52]}$. 进入秋、冬季节, 蓝藻水华 消退, 藻细胞大规模衰亡裂解, 毒素大量释放到水体中, 尤其是 MC-LR 异构体的优先释放和此期间 MCs 的 光和生物降解速度显著下降 ${ }^{[49,53]}$, 造成秋、冬季 EMC-LR 比例增加明显高于夏季, 且高于其他两种异构体. 随着春季 5 月水温升高, 产毒微囊藻又重新恢复生长合成 MCs, 释放到水体中的 EMC-LR 较少, 使春季 EMC-LR 比例明显低于秋、冬季. 由此可见,巢湖在秋、冬季蓝藻消退衰亡阶段水体中 EMCs 的危害更大.

氮、磷营养盐对 MCs 异构体组成比例的影响表现在空间上. 相关分析表明, 氮、磷营养盐浓度与 IMC-RR 所占比例呈显著正相关, 与 IMC-LR 所占比例呈显著负相关 (表 2), 表明巢湖西湖区 IMC-RR 比例较高, 而东 湖区 IMC-LR 比例较高. 而 IMC-YR 所占比例的空间分布没有一定的规律性, 与氮、磷营养盐浓度没有显著 相关性. 研究表明相对于 MC-LR, 高 TP 浓度更有利于 MC-RR 的合成 ${ }^{[54-55]}$. Liu 等 ${ }^{[56]}$ 研究发现氮浓度的增加 也有利于 MC-RR 的合成. 而杨华 ${ }^{[31]}$ 的研究指出高 TP 浓度有利于合成 MC-RR, 而低 TP 浓度有助于合成 MC-LR. 本研究中, 巢湖西湖区氮、磷营养盐浓度明显高于湖心区和东湖区, 更有利于 MC-RR 异构体的合 成, 故西湖区 IMC-RR 比例明显高于湖心区和东湖区 (图 7), 而东湖区低氮、磷浓度有助于合成 MC-LR, 其比 例明显高于湖心区和西湖区. 因此, 巢湖的东湖区更易合成较高比例的 IMC-LR 异构体. 而有趣的是, EMCs 异构体比例空间变化与 IMCs 相反, 氮、磷浓度与 EMC-RR 比例呈显著负相关, 与 EMC-LR 比例呈显著正相 关 (表 2). 可见,EMC-RR 在东湖区比例较高,而西湖区则释放较多生理毒性较强的 EMC-LR 异构体.

可见, 巢湖 IMCs 和 EMCs 主要异构体 MC-LR 和 MC-RR 存在着动态变化过程, 其组成比例的变化反映 了水体中 MCs 的污染程度. EMCs 浓度变化直接关系到水环境健康和周边居民的饮用水安全, 应加强日常监 测, 提高对其关注度, 特别是本研究发现 EMCs 中毒性最强的 EMC-LR 占有最高比例, 且其浓度已经超过世 界卫生组织建议的饮用水浓度的基准值 $(1 \mu \mathrm{g} / \mathrm{L})$, 巢湖 MCs 的污染, 尤其是秋、冬季节水体 EMCs 的浓度已 经严重威胁到饮用水安全. 因此, 加强野外的监测力度实时掌握有害蓝藻和 MCs 污染状况, 有助于提前预测 并降低有害蓝藻发生的规模,保障水生态系统安全.

\section{4 结论}

1) 微囊藻和鱼腥藻是巢湖水华蓝藻优势属, 而微囊藻是 MCs 的主要贡献者.

2) 巢湖 MCs 常见异构体为 MC-RR、MC-LR 和 MC-YR, 其中 MC-RR 和 MC-LR 比例较高, 为主要异构体. IMCs 和 EMCs 异构体及其比例变化呈现不同的时空分布特征. 季节上, IMCs 的 3 种异构体浓度均表现为夏 季>春季>秋季>冬季, 而 EMCs 的 3 种异构体浓度的变化趋势各不同. 空间上, IMCs 和 EMCs 的 3 种异构体 均表现为西湖区>湖心区 $>$ 东湖区. IMCs 异构体组成比例为 IMC-RR $>$ IMC-LR $>$ IMC-YR, IMC-RR 为占比最高 的异构体, EMCs 异构体组成比例为 EMC-LR $>$ EMC-RR $>$ EMC-YR, EMC-LR 为占比最高的异构体. 季节上, IMC-RR 所占比例为秋季 $>$ 夏季 $>$ 春季 $>$ 冬季, 而 EMC-LR 所占比例为冬季 $>$ 秋季 $>$ 春季 $>$ 夏季. 空间上, IMC-RR 和 EMC-LR 所占比例均为西湖区 > 湖心区 >⿻⿻一𠃋小湖区.

3) 相关分析结果显示, 微囊藻生物量、水温和 TP 浓度是影响巢湖 IMCs 和 EMCs 异构体浓度及组成比 例的关键因子.

\section{5 参考文献}

[ 1 ] Paerl HW, Rd FR, Moisander PH et al. Harmful freshwater algal blooms, with an emphasis on cyanobacteria. The Scientif- 
ic World Journal, 2001, 1(1): 76.

[ 2 ] Falconer IR. Tumor promotion and liver injury caused by oral consumption of cyanobacteria. Environmental Toxicology, 2010, 6(2): 177-184.

[ 3 ] Li XY ed. Toxicological research of microcystins. Beijing: Science Press, 2007: 112-116. [李效宇. 微囊藻毒素及其毒 理学研究. 北京: 科学出版社, 2007: 112-116.]

[ 4 ] Chorus I, Bartram J, Chorus I et al. Toxic cyanobacteria in water: a guide to their public health consequences, monitoring and management. Limnology \& Oceanography, 2000, 45(5) : 255-258.

[ 5 ] Dittmann E, Neilan BA, Erhard M et al. Insertional mutagenesis of a peptide synthetase gene that is responsible for hepatotoxin production in the cyanobacterium Microcystis aeruginosa PCC 7806. Molecular Microbiology, 2010, 26(4) : 779-787.

[ 6 ] Stachelhaus T, Marahiel MA. Modular structure of genes encoding multifunctional peptide synthetases required for non-ribosomal peptide synthesis. FEMS Microbiology Letters, 1995, 125(1) : 3.

[ 7 ] Carmichael WW. Cyanobacteria secondary metabolites-the cyanotoxins. Journal of Applied Bacteriology, 2010, 72 (6): 445-459.

[ 8 ] Jochimsen EM, Carmichael WW, An JS et al. Liver failure and death after exposure to microcystins at a hemodialysis center in Brazil. New England Journal of Medicine, 1998, 338(13) : 873-878.

[ 9 ] Song LR, Chen W. Production of microcystins in bloom-forming cyanobacteria and their environment fates: a review. $J$ Lake Sci, 2009, 21 (6) : 749-757. DOI: 10.18307/2009.0601. [宋立荣, 陈伟. 水华蓝藻产毒的生物学机制及毒素 的环境归趋研究进展. 湖泊科学, 2009, 21(6) : 749-757.]

[10] Pearson LA, Mihali TK, Moffitt MC et al. On the chemistry, toxicology and genetics of the cyanobacterial toxins, microcystin, nodularin, saxitoxin and cylindrospermopsin. Marine Drugs, 2010, 8(5) : 1650-1680.

[11] Messineo V, Mattei D, Melchiorre S et al. Microcystin diversity in a Planktothrix rubescens population from Lake Albano (Central Italy). Toxicon Official Journal of the International Society on Toxinology, 2006, 48(2) : 160-174.

[12] Neilan BA, Pearson LA, Moffitt MC et al. The genetics and genomics of cyanobacterial toxicity. Oxygen Transport to Tissue XXXIII, 2008, 619(5): 417-452.

[13] Vijayaraghavan R. Comparative toxicity evaluation of cyanobacterial cyclic peptide toxin microcystin variants (LR, RR, YR) in mice. Toxicology, 2003, 188(2) : 285-296.

[14] Harke MJ, Gobler CJ. Daily transcriptome changes reveal the role of nitrogen in controlling microcystin synthesis and nutrient transport in the toxic cyanobacterium, Microcystis aeruginosa. BMC Genomics, 2015, 16(1): 1068.

[15] Mowe MA, Porojan C, Abbas F et al. Rising temperatures may increase growth rates and microcystin production in tropical Microcystis species. Harmful Algae, 2015, 50: 88-98.

[16] Yu L, Kong FX, Zhang M et al. The dynamics of Microcystis genotypes and microcystin production and associations with environmental factors during blooms in Lake Chaohu, China. Toxins, 2014, 6(12) : 3238-3257.

[17] Shi K, Zhang YL, Xu H et al. Long-term satellite observations of microcystin concentrations in Lake Taihu during cyanobacterial bloom periods. Environmental Science \& Technology, 2015, 49(11) : 6448-6456.

[18] Sivonen K, Evans WR, Carmichael WW et al. Hepatotoxic microcystin diversity in cyanobacterial blooms collected in portuguese freshwaters. Water Research, 1996, 30(10): 2377-2384.

[19] Rapala J, Sivonen K, Lyra C et al. Variation of microcystins, cyanobacterial hepatotoxins, in Anabaena spp. as a function of growth stimuli. Applied and Environment Microbiology, 1997, 63(6) : 2206-2212.

[20] Tonk L, Visser PM, Christiansen G et al. The microcystin composition of the cyanobacterium Planktothrix agardhii changes towards a more toxic variant with increasing light intensity. Applied and Environment Microbiology, 2005, 71 (9) : 5177-5181.

[21] Van DB, Ferreruela G, Tonk L et al. Pulsed nitrogen supply induces dynamic changes in the amino acid composition and microcystin production of the harmful cyanobacterium Planktothrix agardhii. FEMS Microbiology Ecology, 2010, 74(2): 430-438.

[22] Oh HM, Lee SJ, Jang MH et al. Microcystin production by Microcystis aeruginosa in a phosphorus-limited chemostat. Applied and Environment Microbiology, 2000, 66(1):176-179.

[23] Cai JB, Li WQ, Pang Y et al. Relationship between extra-cellular microcystin and intra-cellular microcystin. Journal of Hydraulic Engineering, 2009, 40(3) : 328-334. [蔡金傍, 李文奇, 逢勇等. 水体中溶解性微囊藻毒素与藻类细胞内 
微囊藻毒素的关系研究. 水利学报, 2009, 40(3) : 328-334.]

[24] Chen J, Xie P. Accumulation of hepatotoxic microcystins in freshwater mussels, aquatic insect larvae and oligochaetes in a large, shallow eutrophic lake (Lake Chaohu) of subtropical China. Fresenius Environmental Bulletin, 2008, 17(7A): 849-854.

[25] Chen J, Xie P, Li L et al. First identification of the hepatotoxic microcystins in the serum of a chronically exposed human population together with indication of hepatocellular damage. Toxicological Sciences, 2009, 108(1) : 81-89.

[26] Chen YW, Chen KN, Hu YH. Discussion on possible error for phytoplankton chlorophyll-a concentration analysis using hot-ethanol extraction method. J Lake Sci, 2006, 18(5) : 550-552. DOI : 10.18307/2006.0519. [陈宇炜，陈开宁，胡耀 辉. 浮游植物叶绿素 a 测定的“热乙醇法” 及其测定误差的探讨. 湖泊科学, 2006, 18(5) : 550-552.]

[27] Hu HJ, Wei XY eds. Freshwater algae in china: system, classification and ecology. Beijing: Science Press, 2006. [胡鸿 钧, 魏印心. 中国淡水藻类: 系统、生态及分类. 北京: 科学出版社, 2006.]

[28] Hillebrand H, Dürselen CD, Kirschtel D et al. Biovolume calculation for pelagic and benthic microalgae. Journal of Phycology, 2010, 35(2): 403-424.

[29] Barco M, Lawton LA, Rivera J et al. Optimization of intracellular microcystin extraction for their subsequent analysis by high-performance liquid chromatography. Journal of Chromatography A, 2005, 1074(1) : 23-30.

[30] Zhang M, Zhang YC, Yang Z et al. Spatial and seasonal shifts in bloom-forming cyanobacteria in Lake Chaohu: Patterns and driving factors. Phycological Research, 2016, 64(1): 44-55.

[31] Yang H. Ecological studies on microcystins in Lakes Chaohu and Taihu [Dissertation]. Wuhan: Institute of Hydrobiology, Chinese Academic of Science, 2006. [杨华. 巢湖和太湖微囊藻毒素的生态学研究 [学位论文]. 武汉: 中国科学院 水生生物研究所, 2006.]

[32] Li YX. Succession of Microcystis blooms in lake Chaohu and competition between different bloom-forming cyanobacterial strains [Dissertation]. Wuhan: Institute of Hydrobiology, Chinese Academic of Science, 2013. [李印霞. 巢湖微囊藻水 华演替及不同水华蓝藻竞争的研究 [学位论文]. 武汉: 中国科学院水生生物研究所, 2013.]

[33] Graham JL, Jones JR, Jones SB et al. Environmental factors influencing microcystin distribution and concentration in the midwestern United States. Water Research, 2004, 38(20) : 4395-4404.

[34] Davis TW, Berry DL, Boyer GL et al. The effects of temperature and nutrients on the growth and dynamics of toxic and non-toxic strains of microcystis during cyanobacteriablooms. Harmful Algae, 2009, 8( 5 ) : 715-725.

[35] Ni WM, Zhang JY, Ding TD et al. Environmental factors regulating cyanobacteria dominance and microcystin production in a subtropical lake within the Taihu Watershed, China. Journal of Zhejiang University-Science A: Applied Physics \& Engineering, 2012, 13(4) : 311-322.

[36] Naoshi F, Yuhei I, Norio S et al. Effects of temperature change on algal growth. Environmental Technology, 1994,15 (5) : 497-500.

[37] O'Neil JM, Davis TW, Burford MA et al. The rise of harmful cyanobacteria blooms: The potential roles of eutrophication and climate change. Harmful Algae, 2012, 14(1) : 313-334.

[38] Paerl HW, Huisman J. Climate. Blooms like it hot. Science, 2008, 320(5872) : 57-58.

[39] Li DM, Yu Y, Yang Z et al. The dynamics of toxic and nontoxic Microcystis during bloom in the large shallow lake, Lake Taihu, China. Environmental Monitoring \& Assessment, 2014, 186(5) : 3053-3062.

[40] Song LR, Chen W. Production of microcystins in bloom-forming cyanobacteria and their environment fates: a review. $J$ Lake Sci , 2009, 21(6): 749-757. DOI: 10.18307/2009.0601. [宋立荣, 陈伟. 水华蓝藻产毒的生物学机制及毒素 的环境归趋研究进展. 湖泊科学, 2009, 21(6) : 749-757.]

[41] Chen W, Song LR, Peng L et al. Reduction in microcystin concentrations in large and shallow lakes: water and sedimentinterface contributions. Water Research, 2008, 42(3): 763-773.

[42] Xie LQ, Xie P, Li SX et al. The low TN:TP ratio, a cause or a result of Microcystis blooms? Water Research, 2003,37 (9) : 2073-2080.

[43] Vézie C, Rapala J, Vaitomaa J et al. Effect of nitrogen and phosphorus on growth of toxic and nontoxic Microcystis strains and on intracellular microcystin concentrations. Microbial Ecology, 2002, 43(4) : 443-454.

[44] Rinta-Kanto JM, Konopko EA, Debruyn JM et al. Lake Erie Microcystis : Relationship between microcystin production, dynamics of genotypes and environmental parameters in a large lake. Harmful Algae, 2009, 8(5) : 665-673. 
[45] Kotak BG, Lam AK, Prepas EE et al. Role of chemical and physical variables in regulating microcystin-LR concentration in phytoplankton of eutrophic lakes. Canadian Journal of Fisheries \& Aquatic Sciences, 2000, 57(8) : 1584-1593.

[46] Davis TW, Harke MJ, Marcoval MA et al. Effects of nitrogenous compounds and phosphorus on the growth of toxic and non-toxic strains of Microcystis during cyanobacterial blooms. Aquatic Microbial Ecology, 2010, 61(2) : 149-162.

[47] Su X, Xue Q, Steinman AD et al. Spatiotemporal dynamics of microcystin variants and relationships with environmental parameters in Lake Taihu, China. Toxins, 2015, 7(8) : 3224-3244.

[48] Zheng L, Xie P, Li YL et al. Variation of intracellular and extracellular microcystins in a shallow, hypereutrophic subtropical chinese lake with dense cyanobacterial blooms. Bulletin of Environmental Contamination and Toxicology, 2004, 73 (4) : 698-706.

[49] Zhang W, Lin YQ, Guo DF et al. Influence of different nitrogen and phosphorus concentrations on growth, photosynthesis and microcystin production of Microcystis aeruginosa. Acta Hydrobiological Sinica, 2006, 30(3) : 318-322. [张玮, 林一 群, 郭定芳等. 不同氮、磷浓度对铜绿微囊藻生长、光合及产毒的影响. 水生物学报, 2006, 30(3): 318-322.]

[50] Wang JX, Xie P, Guo NC. Effects of nonylphenol on the growth and microcystin production of Microcystis strains. Environmental Research, 2007, 103(1): 70-78.

[51] Wang FF, Tong C, Yang F et al. Spatial and temporal distribution of microcystins in the Fuzhou Shanzai Reservoir. Acta Scientiae Circumstantiae, 2011, 31(3) : 533-546. [王菲凤, 全川, 杨芳等. 福州山仔水库水华微囊藻毒素时空分布 特征. 环境科学学报, 2011, 31(3): 533-546.]

[52] Yang F, Zhou Y, Sun R et al. Biodegradation of microcystin-LR and-RR by a novel microcystin-degrading bacterium isolated from Lake Taihu. Biodegradation, 2014, 25(3) : 447-457.

[53] Zhang RF, Deng ZR, Wu CT et al. Characteristic of the temporal distribution of dissolved microcystins and its relationships with environmental factors in a typical freshwater shrimp aquaculture pond in South Taihu Area. Freshwater Fisheries. 2018, 48 (5) : 41-47. [张荣飞, 邓泽融, 吴陈涛等. 南太湖地区一典型青虾养殖池塘中微囊藻毒素浓度与环境因 子间的相关性. 淡水渔业, 2018, 48(5): 41-47.]

[54] Yang H, Xie P, Xu J et al. Seasonal variation of microcystin concentration in Lake Chaohu, a shallow subtropical lake in the People's Republic of China. Bulletin of Environmental Contamination \& Toxicology, 2006, 77(3) : 367-374.

[55] Zhang M. The space-time distribution characteristics, causes and degradtion technology research of microcystin in Taoranting lake[Dissertation]. Dalian: Dalian Ocean University, 2014. [张默. 陶然亭湖微囊澡毒素时间分布特征、成因及降 解技术研究 [学位论文]. 大连: 大连海洋大学, 2014.]

[56] Liu J, Van OE, Faassen EJ et al. Elevated $\mathrm{pCO}_{2}$ causes a shift towards more toxic microcystin variants in nitrogen limited Microcystis aeruginosa. FEMS Microbiology Ecology, 2015, 92(2). DOI: 10.1093/femsec/fiv159. 